\title{
Da ontogênese à filogênese: uma velha diretriz metodológica de Freud em Além do princípio do prazer
}

\author{
From ontogeny to phylogeny: Freud's old methodological guideline in \\ 'Beyond the Pleasure Principle'
}

\section{Marcelo Galletti Ferretti*}

Resumo: Este trabalho visa a mostrar que se pode identificar uma diretriz metodológica a qual guia as especulações de Freud em Além do princípio do prazer e que foi concebida pelo autor no manuscrito de 1895 Projeto de uma psicologia. Ela se prestou a criar condições para o recurso a explicações de ordem ontogenética e filogenética para os fenômenos detectados pela clínica freudiana. A fim de mostrar esses aspectos, primeiramente se resgata a referida diretriz em Projeto de uma psicologia e se a identifica, em seguida, em Além do princípio do prazer Com isso, busca-se contribuir não apenas para o esclarecimento dos recursos freudianos à filogênese e à ontogênese como também para o vislumbre da importância desses domínios na metapsicologia freudiana e das possibilidades de relação entre a psicanálise e a biologia que se abrem a partir desse belo e desafiador ensaio de Freud escrito há um século.

Palavras-chave: Freud; Filogênese; Ontogênese; Especulação; Biologia; Evolução

Abstract: This paper aims to show that a methodological guideline can be identified which guides Freud's speculations in Beyond the Pleasure Principle and that was conceived by the author in the 1895 manuscript Project of a psychology. This guideline created conditions for explanations of an ontogenetic and phylogenetic order for the phenomena discovered by Freud in his clinical activity. In order to show these aspects, we rescue that guideline in Project of a psychology first and then identify it in Beyond the Pleasure Principle. With this, we seek to provide contributions to clarify Freudian resources to phylogeny and ontogeny, as well as give a glimpse to the importance of these domains in Freudian metapsychology and the possibilities of a dialog between psychoanalysis and biology through this beautiful and challenging essay by Freud written a century ago.

Keywords: Freud; Phylogeny; Ontogeny; Speculation; Biology; Evolution

No escrito de Freud cujo centenário ora celebramos, o expediente a hipóteses filogenéticas - isto é, a especulações de caráter evolucionário - desempenha uma função capital. O motor de tal expediente é a postulação de uma natureza conservadora da pulsão, 
atributo, por sua vez, captado pela clínica psicanalítica mediante as mais variadas formas de manifestação do que o fundador da psicanálise chamou de compulsão à repetição (Wiederholungszwang). Porém, de acordo com o autor, esse atributo poderia ser observado em toda forma de vida, como o testemunhariam fenômenos da embriologia, da hereditariedade e do comportamento reprodutivos dos animais, de forma que aquela descoberta da experiência analítica parecia se ancorar no âmago do vivente.

$\mathrm{O}$ recurso à filogênese merece interesse porque é axial na obra freudiana e no entanto ainda relegado por boa parte daqueles que a investigam. Frank J. Sulloway já havia mostrado essa importância em seu Freud, biologist of the mind, publicado mais de quarenta anos atrás - e nunca vertido para o português curiosamente -, mas ela permanece menosprezada, sobretudo entre os praticantes da psicanálise. Pouco anos antes de morrer, Jean Laplanche, que jamais cessou de ressaltar tal importância, conquanto em chave bem diferente da de Sulloway, ainda denunciava tal desdém: “esse tema central para Freud é completamente esquecido em suas consequências pela maior parte dos psicanalistas”.

Além do princípio do prazer fornece elementos cruciais ao delineamento do recurso à filogênese na obra freudiana, o qual, por sua vez, não pode ser compreendido sem o recurso à ontogênese - isto é, ao que se passa no âmbito que compreende a vida do organismo. De fato, como procurarei mostrar a seguir, no manuscrito de 1895 Projeto de uma psicologia Freud concebeu uma diretriz metodológica para guiar o recurso a cada um desses domínios. Ao passo que "muito já se disse sobre o modo como as teses metapsicológicas mais importantes encontram-se prefiguradas nesse manuscrito" ${ }^{2}$, pouca atenção lhe foi dada do ponto de vista que se proporá abaixo. Ainda, porquanto uma porção essencial dessas teses foi erigida a partir de tal ponto de vista, retoma-lo implica também recuperar traços não tão destacados da metapsicologia freudiana.

Eis o que pretende este artigo, o qual, primeiramente, resgatará a referida diretriz em Projeto de uma psicologia e, em seguida, em Além do princípio do prazer com o intuito de buscar fornecer contribuições não apenas para o esclarecimento dos recursos freudianos à filogênese e à ontogênese como também ao vislumbre da importância desses domínios na metapsicologia freudiana e, ainda, das possibilidades de relação entre a psicanálise e a biologia que se abrem a partir desse belo e desafiador ensaio de Freud publicado há um século.

\footnotetext{
${ }^{1}$ LAPLANCHE, Introduzione al tema della filogenesi, 901.

${ }^{2}$ CAROPRESO \& SIMANKE, Compulsão à repetição: um retorno às origens da metapsicologia freudiana, 208.
} 


\section{Ontogênese e filogênese em Projeto de uma psicologia: do mecânico ao biológico}

Ao menos desde o alerta perspicaz de James Strachey, em nota apensa ao então recém-descoberto Projeto de uma psicologia, pôde-se perceber de modo mais imediato que o manuscrito se pauta por explicações ora denominadas mecânicas, ora chamadas biológicas $^{3}$. Grosso modo, ao passo que as primeiras aduzem às leis gerais do movimento e do equilíbrio, as últimas recorrem ao aspecto genético e ao valor adaptativo de um determinado fenômeno ou ação. Ainda assim, nem sempre se reteve essa distinção: não foi infrequente pensar que o texto constava de um modelo explicativo apenas, de caráter estritamente "neurológico" 4 . De fato, salvo raros momentos, tais explicações permanecem implícitas de maneira geral, e a relação entre elas, subentendida, de modo que o próprio Freud não oferece qualquer tratamento sistemático sobre a questão. Em contrapartida, uma leitura mais atenta do escrito acusa a diferença entre as duas espécies de explicação nele presentes. Mais difícil, porém, é a compreensão da relação entre elas e do papel crescente que uma delas - a biológica, ao contrário do que possa parecer - adquire à medida que Freud procura resolver os impasses em que sua teoria redunda.

A julgar pela tarefa a que o texto se propõe, seu interesse gravita sobre as explicações mecânicas especialmente. Logo nas primeiras linhas, lemos que o propósito do manuscrito é "fornecer uma psicologia como ciência natural [eine naturwissenschaftliche Psychologie], isto é, apresentar os processos psíquicos como estados quantitativamente determinados de partes materiais que podem ser especificadas [...]"5. O texto, assim, anuncia que buscará escorar seus desenvolvimentos subsequentes na ideia central de que os processos psíquicos resultam do deslocamento de quantidades entre partes materiais, isto é, neurônios que configuram o sistema nervoso. Trata-se, basicamente, de examinar o funcionamento psíquico a partir das noções de quantidade e matéria e, portanto, à luz de causas naturais. Dessa forma, ao buscar constituir sua psicologia, Freud mira a Física - a de Galileu e a de Newton em especial, segundo Gabbi Jr. ${ }^{6}$-, a qual baliza a construção teórica freudiana a partir certos princípios clássicos.

Contudo, Freud, ciente de que a neurologia não podia ser inteiramente reduzida a uma mecânica, tendo sido erigida também sobre ideias evolucionistas ${ }^{7}$, dá mostras claras de estar atento a um viés não-mecanicista desde o início do Projeto. Logo na seção subsequente à introdução, o autor examina a função nervosa do ponto de vista do desenvolvimento, o que revela os limites da explicação mecânica. De fato, ele busca

\footnotetext{
${ }^{3}$ FREUD, Entwurf einer psychologie, 398, n.1.

${ }^{4}$ SULLOWAY, Freud, biologist of the mind, 120-123.

${ }^{5}$ FREUD, Entwurf einer psychologie, 387.

${ }^{6}$ GABBI JR., Notas a Projeto de uma psicologia, 23.

${ }^{7}$ Como mostra YOUNG, Mind, brain, and adaptation in the nineteenth century: cerebral localization and its biological context from Gall to Ferrier.
} 
mostrar que o referido aspecto pode ser elucidado pela postulação de um princípio mecânico considerado fundamental: o princípio da inércia, que reza que o neurônio tende a se libertar de uma dada quantidade que lhe aflui. Dessa forma, pretende-se que esse princípio possa franquear a compreensão da "função [Funktion] \{neuronal\} em sua totalidade" escoada. A introdução da noção biológica de função parece marcar uma passagem sutil do domínio mecânico ao domínio biológico. Aparentemente, Freud tenciona subsumir este àquele, explicando a função pelo mecanismo. Afinal, dois aspectos dos neurônios - a estrutura $(B a u)$ e as operações (Leistungen) nervosas - são, de imediato, explicáveis pelo princípio da inércia: a estrutura bipartida em uma porção sensorial e outra motora e o modo reflexo de operar - características verificadas desde o nível neuronal até a totalidade do sistema nervoso - são aspectos imanentes à mecânica do escoamento. Porém, a compreensão do desenvolvimento (Entwicklung) da função nervosa requer o recurso a elementos que transcendem essa mecânica e que devem ser buscados noutro lugar. É preciso recorrer à biologia e recuar no tempo, recuperando as semelhanças entre os organismos, para que se possa vislumbrar o desenvolvimento da função reflexa:

Se, desde aqui, recuar-se mais longe, vinculou-se o sistema nervoso inicialmente, como herdeiro da irritabilidade [Reizbarrkeit] geral do protoplasma, à superfície externa irritável \{de um organismo\}, que é interrompida por vastos segmentos \{de superfície\} não-irritáveis 9 .

Tal declaração, como Simanke ${ }^{10}$ indica, denota o avanço de uma concepção biológica de contornos filogenéticos acerca da função reflexa, que remete, mais imediatamente, a uma ideia expressa por Meynert em seu manual Psychiatrie. Ao comparar o sistema nervoso humano (o córtex cerebral, mais precisamente) a organismos constituídos de uma massa homogênea e informe de protoplasma, tais como a ameba, Meynert evidencia que, como os pseudópodes do organismo ameboide, os prolongamentos sensíveis e motores do córtex (nervos, músculos, esqueleto, enfim, todas as estruturas da periferia corporal) percebem o mundo exterior e agem sobre este. A declaração reproduzida acima aponta que, recuando no tempo, intuímos que a porção receptora nervosa se tornou uma estrutura interna ao organismo em um dado momento da evolução, embora se tenha mantido vinculada ao ambiente por meio de prolongamentos sensíveis e motores. Tal vínculo pode ser encarado como testemunho da herança da irritabilidade,

\footnotetext{
${ }^{8}$ FREUD, Entwurf einer psychologie, 388. Os termos entre chaves representam adições dos editores da edição em questão.

${ }^{9}$ FREUD, Entwurf einer psychologie, 388-389, grifos meus.

${ }^{10}$ SIMANKE, Mente, cérebro e consciência nos primórdios da metapsicologia freudiana: uma análise do Projeto de uma Psicologia, 17.
} 
apanágio, afinal, da substância viva mais primordial, o protoplasma, que tem como propriedade fundamental reagir a estímulos das mais variadas naturezas.

$\mathrm{O}$ avanço de tais considerações inaugura o enfoque biológico, que reverberará através de todo manuscrito. Todavia, deve-se notar que tal enfoque caminha pari passu ao enfoque mecânico, de modo que o exame dos aspectos mais cruciais do aparelho neuronal - desde sua morfologia até fenômenos complexos que nele se originam, como a consciência - deve resultar do cotejamento dos dois enfoques. Em certo sentido, a apropriação da comparação de Meynert sinaliza que reafirmar o caráter reflexo da ação nervosa não implica negar a origem filogenética dessa função, o que prenuncia que evolução e mecanismo não devem ser aspectos excludentes. Pelo contrário, estes devem compor a urdidura do texto, cerzidos a partir da "premissa básica de que o organismo é um sistema material que evoluiu (isto é, possui uma história)"11.

O final da primeira seção já exibe os dois enfoques como pilares do raciocínio que organiza o escrito. Primeiramente, tais enfoques informam os conceitos de função primária e secundária, que são então introduzidos. Ao passo que a primeira diz respeito à função de eliminação ou descarga $(A b f u h r)$ da atividade nervosa, a segunda corresponde à conservação das vias de eliminação que propiciaram a "fuga de estímulo" (Reizflucht), isto é, o afastamento do organismo da fonte de estímulo. Porquanto Freud afirma que, com a função primária, "há lugar para o desenvolvimento [Entwicklung] da função secundária"12, inferimos que esta decorre daquela e corresponde a uma aquisição biológica que se dá ao longo do tempo. Uma aquisição dessa espécie, porém, não pode ocorrer num sistema regido pelo princípio da inércia. Ora, sob o império desse princípio, não há lugar para a vida, pois um sistema que visa apenas à descarga não pode propiciar o armazenamento do quantum que toda atividade vital - ou, de acordo com a formulação freudiana, a “necessidade da vida” (Not des Lebens) - requer. Donde Freud afirmar que o organismo é guiado por outro princípio "desde o início [vom Anfang]"13, ou seja, a partir do advento do próprio organismo e seu funcionamento vital. A esse outro princípio, sob cujo império o organismo retém quantidade necessária a atividades vitais básicas - fome e sexualidade, cuja satisfação é tarefa de uma ação denominada específica -, embora a mantenha no nível mais baixo possível e estável, Freud dá o nome de princípio da constância. Como na distinção das funções primária e secundária, a diferenciação dos princípios da inércia e da constância se apoia na diferenciação entre enfoques, respectivamente, de natureza mecânica e biológica.

\footnotetext{
11 SIMANKE, Mente, cérebro e consciência nos primórdios da metapsicologia freudiana: uma análise do Projeto de uma Psicologia, 41, grifos do autor.

${ }^{12}$ FREUD, Entwurf einer psychologie, 389, grifo meu.

${ }^{13}$ FREUD, Entwurf einer psychologie, 389, grifos meus.
} 
Ao cabo do exame de uma terceira distinção, que vem a coroar a série organizada a partir de tais enfoques, Freud explicita a orientação de cotejá-los. Trata-se da distinção entre dois sistemas neuronais, chamados de $\phi$ e $\psi$, responsáveis, respectivamente, pela percepção e pela memória. Retomemos muito brevemente, pois, o movimento argumentativo dedicado a fundamentar a suposição da existência desses dois sistemas. Visto que o sistema nervoso possui a capacidade de, ao mesmo tempo, memorizar e perceber, isto é, reter permanentemente as alterações que resultam dos processos condutivos e permanecer receptivo aos estímulos, supõe-se, naturalmente, que dois sistemas diferentes realizem essas funções. Porém, a diferença entre eles não pode repousar sobre a morfologia dos neurônios, porque, conforme se viu, estes são arquitetados de um mesmo modo cujo fim é escoar a quantidade, e não há provas que confirmem uma suposição contrária. Se os elementos de tais sistemas são idênticos do ponto de vista constitucional, então o que deve diferenciá-los é algo contingente: seu comportamento ante diferentes quantidades. Considerando-se que a magnitude dos estímulos que provêm do mundo externo é sempre maior do que a das excitações que percorrem o interior do organismo, e que entre os neurônios há um tecido intersticial, menos apropriado para a condução se comparado ao protoplasma e, por isso, denominado por Freud "barreira de contato" (Kontaktschrank), a quantidade maior a que é submetido o sistema $\phi$, voltado para o ambiente, possui magnitude suficiente para romper as barreiras de contato. Essa ruptura, de outra parte, não ocorre com o sistema $\psi$, que, submetido a menores quantidades, retém parte destas na forma de traços de memória. Toda essa argumentação garante que a diferença entre os dois sistemas em questão seja fundamentada não apenas nessa explicação mecânica como também numa explicação biológica, já que o advento de um sistema de memória - o qual, por exemplo, permite ao organismo reconhecer alimentos ou predadores - possui grande valor de sobrevivência. Daí Freud concluir que, com tal argumentação, “a semelhança essencial entre os neurônios $\phi$ e $\psi$ é salva, e sua diferença em relação à permeabilidade, explicada biológica e mecanicamente" ${ }^{14}$.

Uma leitura atenta pode derivar dessa argumentação a orientação geral freudiana de contemplar os dois tipos de explicação e, assim, constatar algo capital à estratégia empregada no manuscrito, mas, se olharmos com atenção para determinados aspectos, tal argumentação pode nos oferecer ainda mais.

Em primeiro lugar, ela nos aponta uma distinção entre os domínios da filogênese e da ontogênese. Antes de iniciar a justificativa da diferenciação proposta entre os sistemas $\phi$ e $\psi$, Freud afirma que o fundamento (Grund) de tal diferenciação deve ser extraído "do desenvolvimento biológico do sistema nervoso, que é, para o investigador da natureza, algo

${ }^{14}$ FREUD, Entwurf einer psychologie, 398, grifos meus. 
que, como tudo mais, forma-se gradualmente" ${ }^{15}$. Com essa afirmação, o autor explicita que a diferenciação em questão deve se dar no plano do desenvolvimento, isto é, durante a ontogênese do organismo. Porém, tal afirmação também abriga o imperativo geral de assentar o estudo do sistema nervoso sobre o preceito do gradualismo, cujo eixo temporal deve compreender tanto o domínio ontogenético quanto o filogenético. Ora, de acordo com esse imperativo, a razão última da diferenciação entre $\phi$ e $\psi$ deve ser buscada na filogênese. Desse modo, $\psi$ teria resultado da evolução - sobre cujas etapas Freud se permite especular a partir de dados anatômicos - de uma parte de $\phi$. Todavia, conforme o exposto, o organismo não apresenta dois sistemas morfológica e constitucionalmente diferentes: são as quantidades a que eles são submetidos que desenvolvem a diferenciação. Tais quantidades, pois, operam durante a ontogênese do organismo determinando os caminhos neurais formados à medida que a experiência franqueia novas aquisições, isto é, aprendizagens. Dessa forma, depreendemos uma distinção entre o âmbito da filogênese do sistema nervoso e o da ontogênese dos caminhos neurais ${ }^{16}$.

Relacionando essa distinção àquela estabelecida entre os dois tipos de explicação que organizam a argumentação do manuscrito, notamos, em seguida, que as explicações mecânicas operam no domínio ontogenético, ao passo que as explicações biológicas evocam o domínio filogenético. Se as aprendizagens representam aquisições ontogenéticas e são elucidadas por uma explicação mecânica (o fluxo de quantidades), assiste-se ao destaque dessa espécie de explicação na abordagem da ontogênese. Por outro lado, se o exame do processo evolutivo implica uma explicação biológica (a vantagem adaptativa de sistemas que desempenham diferentes funções), tal explicação ganha alcance no plano filogenético. É nessa medida que podemos apontar uma correspondência entre os domínios e as explicações em questão.

Por fim, e isto é o que nos interessa mais no presente artigo, podemos constatar que não se pode apelar para o enfoque biológico sem antes esgotar o poder explicativo do enfoque mecânico. Freud torna essa orientação mais explícita ao invocar e rejeitar logo em seguida a explicação biológica para a distinção entre $\psi$ e $\phi$. Ele declara que o apelo ao fator constitucional implica uma arbitrariedade - já que tal apelo viola o preceito da identidade entre os neurônios -, mas faz a seguinte ressalva: “[...] embora [obwohl se pudesse invocar, segundo as linhas darwinianas de pensamento, a indispensabilidade e, por conseguinte, a sobrevivência dos neurônios impermeáveis"17. O uso da conjunção concessiva "embora" deixa clara a admissão da pertinência dessa hipótese de inspiração darwiniana. Assim, a impermeabilidade, muito provavelmente, tornou-se vantajosa aos organismos que a

\footnotetext{
${ }^{15}$ FREUD, Entwurf einer psychologie, 395, grifos meus.

${ }^{16}$ SIMANKE, Mente, cérebro e consciência nos primórdios da metapsicologia freudiana: uma análise do Projeto de uma Psicologia, 41.

${ }^{17}$ FREUD, Entwurf einer psychologie, 396, grifo meu.
} 
possuíam, motivo pelo qual deve ter sido selecionada e mantida no patrimônio genético das espécies. A questão é que não é lícito apelar em primeiro lugar para essa explicação de forte teor especulativo, porquanto a explicação mecânica parece ser mais simples e evidente - ou, segundo a qualificação de Freud, “despretensiosa [anspruchsloser]”. De certa forma, essa orientação já vinha se insinuando desde o momento no qual o autor recorreu ao conceito biológico de desenvolvimento para suprir os limites explicativos da mecânica do escoamento. Por outro lado, tal orientação será completamente explicitada mais à frente, quando da caracterização da explicação biológica como um fundamento explicativo (Erklärungsgrund) "que deve ter validade independente, ainda que não exclua uma redução a princípios mecânicos (fatores quantitativos), mas a exija"18. De todo modo, com o reconhecimento da validade de um raciocínio evolutivo para a permeabilidade relativa de $\psi$ e o arrolamento subsequente de uma explicação menos rebuscada Freud já nos mostra que, na ordem das razões do Projeto, o ponto de vista mecânico deve ser exaurido antes do recurso ao biológico.

Relendo tal diretriz metodológica à luz da correspondência estabelecida acima, concluímos que a filogênese somente pode ser invocada após se ter esquadrinhado a ontogênese. Por conseguinte, conforme Simanke aponta, as lacunas da explicação ontogenética são ocasião para o recurso às hipóteses filogenéticas. Isto é, trata-se de empreender uma "teoria sobre aquilo que é adquirido pelo indivíduo e erigido sobre sua herança biológica e que deve poder, a princípio, ser explicado mecanicamente, antes que as considerações biológicas e filogenéticas entrem em cena para completar a explicação" ${ }^{19}$. Assim, o que a argumentação dedicada a diferenciar $\phi$ e $\psi$ denota não é a presença de dois modelos explicativos simplesmente, mas a tentativa - a primeira na obra freudiana - de equacionar tais modelos e, com isso, os domínios ontogenético e filogenético.

$\mathrm{Na}$ verdade, a despeito do anúncio da precedência da explicação mecânica, o que se testemunha no manuscrito é, de fato, a progressiva centralidade da explicação biológica. Esta começa a ganhar destaque com a elucidação dos mecanismos da defesa primária e, em seguida, da atenção na primeira parte do manuscrito, e torna-se basal na terceira parte. Com efeito, nesta Freud declara que a explicação biológica é a única encontrável, pelo que esses mecanismos são então qualificados, pura e simplesmente, de "regras biológicas". A respeito da defesa primária, o autor admite sua evidente incapacidade de apresentá-la mecanicamente, o mesmo problema que enfrentou ao procurar explicar a atenção, motivos que o levam a entronizar o enfoque biológico nesses casos.

Deve-se ressaltar que a constatação do peso o qual a explicação biológica ganha em Projeto de uma psicologia não implica, de modo algum, a invalidação da diretriz

\footnotetext{
${ }^{18}$ FREUD, Entwurf einer psychologie, 415.

${ }^{19}$ SIMANKE, Mente, cérebro e consciência nos primórdios da metapsicologia freudiana: uma análise do Projeto de uma Psicologia, 66.
} 
metodológica identificada acima. Pelo contrário: significa reafirmá-la, já que a ênfase dada a tal explicação decorre do esgotamento da explicação mecânica. Portanto, deve-se compreender que o recurso à explicação biológica em nesse manuscrito de 1895 não é, em absoluto, uma solução apressada e indevida, um deus ex-machina.

\section{Da ontogênese à filogênese em Além do princípio do prazer}

Os três primeiros capítulos de Além do princípio do prazer são dedicados à construção do problema que justifica a tarefa do quarto capítulo, que é a de se debruçar sobre a gênese e a estrutura do aparelho psíquico (seelisch Apparat) - justamente a tarefa de Projeto de uma psicologia. Como ocorre em Freud frequentemente, conforme bem observou Monzani ${ }^{20}$, o problema é construído a partir de uma série que justifique sua necessidade de investigação. Trata-se de aspectos revelados pela clínica - a neurose e o sonho traumáticos, as brincadeiras infantis e a compulsão à repetição que se materializa na transferência negativa em certas análises - os quais, tomados em conjunto apenas, autorizavam a suposição de que "na vida anímica há, de fato, uma compulsão à repetição, que suplanta o princípio do prazer" ${ }^{21}$. Um fenômeno de tal monta, que parece lançar suspeições sobre esse princípio - um dos alicerces do edifício psicanalítico - exige que se examine sua fundação - o que quer dizer remontar à origem do próprio aparelho psíquico.

É o encaminhamento desse problema que exige o que Freud reitera, desde o início do quarto capítulo e com todas as ressalvas, ser da ordem da especulação (Spekulation). Dessa forma, deve-se compreendê-la como um avanço de hipóteses acerca da gênese do aparelho psíquico, isto é, de seu desenvolvimento e de sua evolução. De fato, para se referir a essas duas dimensões temporais, Freud emprega (repetidas vezes no texto) uma mesma palavra, Entwicklung, que tem esses dois sentidos na língua alemã, mas veremos que é possível diferenciar os dois de acordo com o que se diz. No momento, é preciso deixar claro que a especulação no texto em questão não se reduz, de modo algum, a um mero exercício metafísico. Monzani já desfez o equívoco dessa redução ${ }^{22}$, assim como Giacoia Junior mais recentemente, ao frisar que a especulação ali deve ser entendida "em sentido consentâneo com os ideais positivistas" de fidelidade às bases observacionais e clínicas da experiência ${ }^{23}$. Contudo, é preciso dar um passo além e mostrar que a especulação freudiana em Além do princípio do prazer, mais do que não ser simplesmente metafísica ou ser "positivista”, é genética. Daí o papel central da biologia, devidamente reconhecido pelo

\footnotetext{
${ }^{20}$ MONZANI, Freud, o movimento de um pensamento, 155-156.

${ }^{21}$ FREUD, Jenseits des Lustprinzips, 233.

${ }^{22}$ MONZANI, Freud, o movimento de um pensamento, 148-52, 228-232.

${ }^{23}$ GIACOIA JUNIOR, Além do princípio do prazer: um dualismo incontornável, 25.
} 
autor ao final do texto, quando frisa que houve a "necessidade [Nötigung] de fazer empréstimos da ciência biológica" ${ }^{24}$.

Dessa maneira, o quarto capítulo inicia a especulação genética de Freud acerca do aparelho psíquico, a qual possui uma série de semelhanças com a do Projeto de uma psicologia. O autor faz a remissão explícita ao esquema inserido na "parte especulativa de meu [seu] Interpretação dos sonhos" ${ }^{25}$, mas, como mostraram Caropreso e Simanke, o liame com o manuscrito de 1895 é mais profundo, uma vez que se trata de retomar vários aspectos da vivência de dor, deixados de lado desde Interpretação dos sonhos, a fim de se caracterizar a noção de trauma ${ }^{26}$. De nossa parte, resta-nos estreitar ainda mais esse liame ao ressaltar a retomada freudiana da mesma hipótese da massa homogênea e informe de protoplasma, destacada mais acima, desta vez sustentada pela teoria da recapitulação do zoólogo Ernst Haeckel:

A embriologia, como repetição da evolução [Entwicklungsgeschichte], mostra realmente que o sistema nervoso central advém [hervorgehen] do ectoderma e que a substância cinzenta do córtex cerebral é ainda uma derivação [Abkömmling] da superfície primitiva e poderia ter herdado [durch Erbschaft übernehmen] características essenciais desta ${ }^{27}$.

Eis a chamada "lei biogenética" postulada por Haeckel, segundo a qual a ontogênese seria uma breve e rápida recapitulação da filogênese. Como vemos, é ela que confere realidade, para Freud, à hipótese da massa protoplasmática. Reparemos na série de termos - "advém”, “derivação", "herdado" - que indicam o apontamento reiterado da dimensão filogenética que sustenta essa hipótese.

Todavia, a tarefa do capítulo em questão é a de promover uma incursão não filogenética - o que é feito no capítulo seguinte efetivamente -, e sim ontogenética. Tratase de abordar o problema do traumatismo, pois Freud elegeu de início as manifestações oníricas da neurose traumática como as mais significativas para o exame da compulsão à repetição. Mais especificamente, trata-se de investigar a maneira como o trauma pode colocar o equilíbrio do aparelho psíquico em perigo. A hipótese da massa protoplasmática é avançada a fim de se descrever a gênese da consciência e de suas peculiaridades excitatórias, bem como da formação de uma camada protetora contra estímulos. O trauma corresponde a uma falha nesse sistema de proteção, à qual se segue uma mobilização contra o excedente de energia. Essa mobilização consiste não em escoá-la, mas em ligá-la

\footnotetext{
${ }^{24}$ FREUD, Jenseits des Lustprinzips, 268, grifo meu.

${ }^{25}$ FREUD, Jenseits des Lustprinzips, 235.

${ }^{26}$ CAROPRESO \& SIMANKE, Compulsão à repetição: um retorno às origens da metapsicologia freudiana, 216-221.

${ }^{27}$ FREUD, Jenseits des Lustprinzips, 236.
} 
(binden). Essa função é "mais primitiva [ursprünglicher]"28 que a do princípio do prazer, de forma que o "além do princípio do prazer" seria esse "período anterior [Vorzeit]"29, isto é, um modo de funcionamento mais originário do aparelho psíquico. Portanto, o trauma seria o retorno a um modo de funcionamento psíquico anterior do ponto de vista ontogenético.

Encontramos, assim, uma primeira resposta às suspeições lançadas sobre o princípio do prazer. A constatação da função mais primitiva de ligação de energia do aparelho psíquico explica a repetição nos sonhos traumáticos, que "buscam restaurar o domínio do estímulo [Reizbewältigung] por meio do desenvolvimento de angústia [...]"30. Quer dizer, nos sonhos traumáticos o que se vê é, na verdade, uma tentativa de ligação. Ora, tal função não destrona o princípio do prazer. De fato, Freud postula que este e aquela são coexistentes e que correspondem a duas funções diferentes do aparelho psíquico, uma das quais (a de ligação) tem a precedência sobre a outra quando da ocorrência traumática, mas que, em condições diferentes desta, trabalham uma a favor da outra. Nesses termos, o princípio do prazer está a salvo e os alicerces do edifício psicanalíticos, intactos.

Contudo, resta retomar os dois outros fenômenos - as brincadeiras infantis e a compulsão à repetição verificada em certas análises - que compõem a série enunciada no início do texto, e é nesse movimento que veremos o último deles provocar embaraços à explicação ontogenética. Nas brincadeiras infantis, as repetições são, com efeito, ou aliadas de exercícios prazerosos (como jogos com o adulto e a escuta de histórias por ele contadas) ou ensaios de domínio sobre a vivência de desprazer, as quais transformam a passividade em atividade, o que indica que o princípio do prazer não é contrariado nesse caso. Já as repetições das vivências traumáticas nas análises desconsideram esse princípio "de todas as maneiras [in jeder Weise]" 31 . O que se vê nesses casos é um verdadeiro fracasso da atividade de ligação, manifestado na relação transferencial negativa com comportamentos infantilmente repetitivos que obstam demasiadamente o tratamento. Esses tipos de repetições, portanto, opõem-se ao princípio do prazer e não podem ser explicados por meio de uma análise ontogenética.

É nesse momento que intervém a explicação filogenética, a qual é buscada na essência da pulsão (Trieb). Com efeito, trata-se de uma característica desta até então não enunciada claramente nas publicações de Freud, por isso destacada por ele: "Uma pulsão [Trieb] seria um impulso [Drang], presente em todo organismo vivo, de restauração de um estado anterior, ao qual o vivo renunciou por influência de forças perturbadoras externas [...]"32. É nesse momento que o autor evoca outros fenômenos vitais para dar provas do "condicionamento histórico [historische Bedingtheit]" e da "natureza conservadora do

\footnotetext{
${ }^{28}$ FREUD, Jenseits des Lustprinzips, 242.

${ }^{29}$ FREUD, Jenseits des Lustprinzips, 242.

${ }^{30}$ FREUD, Jenseits des Lustprinzips, 241.

${ }^{31}$ FREUD, Jenseits des Lustprinzips, 246, grifo do autor.

${ }^{32}$ FREUD, Jenseits des Lustprinzips, 246, grifos do autor.
} 
vivente [konservativen Natur des Lebenden]"33: a piracema dos peixes, os voos das aves migratórias, os fenômenos da hereditariedade e os fatos da embriologia. A lei biogenética é então invocada novamente e os termos freudianos para a designação das dimensões ontogenética e filogenética aparecem:

Vemos que o germe de um animal vivo é forçado a repetir em seu desenvolvimento [Entwicklung] - ainda que de maneira abreviada e fugaz as estruturas de todas as formas [Formen] de que o animal provém, ao invés de seguir o caminho mais curto até sua forma [Gestaltung] definitiva, e apenas em mínima parte podemos explicar mecanicamente [mechanisch erklären] esse comportamento, não podendo deixar de lado a explicação histórica [historische Erklärung] $]^{34}$.

Vemos que a teoria haeckeliana da recapitulação vem novamente ao socorro da sustentação da argumentação de Freud, mas, dessa vez, trata-se de um momento capital do texto, que sinaliza o esgotamento do poder explicativo das hipóteses ontogenéticas e a necessidade de apelo às filogenéticas. Reparemos que, como em Projeto de uma psicologia, Freud emprega o termo "mecânicas" para designar as primeiras. Quanto às últimas, Freud as designa como "históricas", o que é bastante compreensível, dado o recuo temporal que elas requerem. O autor deixa a designação "biológicas" para as explicações dos cientistas que evocará no capítulo seguinte, a fim de estabelecer com eles um diálogo em busca de uma sustentação às especulações filogenéticas.

São tais especulações, portanto, que levam Freud a sondar as considerações da biologia sobre a morte e sua inscrição na substância viva. Para os fins de nossa discussão, interessa menos retomar as teses dos autores do que a função que elas ocupam no texto freudiano. Antes disso, no entanto, devemos lembrar, graças à análise pormenorizada de Ulrike May, que o sexto capítulo foi acrescentado apenas na segunda, a última versão antes da publicação, de Além do princípio do prazer, escrita em agosto de 1920. Na primeira versão, redigida entre abril e maio de 1919, havia todos os capítulos da versão impressa, exceto o sexto. Desse modo, na primeira versão do texto não há menção à biologia ou à filosofia e, por conseguinte, nem a "Schopenhauer, Platão, Fechner, Weismann, Lipschütz, Doflein, Max Hartmann ou Fliess”35 - enfim, nenhum autor a quem Freud recorre em sua discussão filogenética. Remontando aos anos de trocas de cartas e ideias entre Freud e Ferenczi, os quais chegaram a esboçar uma obra conjunta sobre as relações entre a psicanálise e a biologia evolucionária (Lamarck, nomeadamente), May observa que a volta dessa troca de ideias com Ferenczi após o rascunho da primeira versão explicaria a ampla

\footnotetext{
${ }^{33}$ FREUD, Jenseits des Lustprinzips, 246, grifo do autor.

${ }^{34}$ FREUD, Jenseits des Lustprinzips, 247, grifos meus.

${ }^{35}$ MAY, The third step in drive theory: on the genesis of Beyond the pleasure principle, 223.
} 
incursão à biologia apenas na segunda versão do texto ${ }^{36}$. Essa observação se coaduna com a diretriz metodológica a qual estamos a identificar, na medida em que indica que, inclusive segundo a cronologia da redação do texto, a especulação filogenética teria vindo mais abertamente num momento posterior.

Como se dizia, interessa-nos a função das considerações biológicas. Quem busca acompanhar atentamente a complicada trama que elas formam não pode deixar de se decepcionar ao ler, logo depois da invocação do então mais eminente biólogo darwiniano a estudar o problema da morte, Auguste Weismann, que "o aparecimento de uma convergência significativa [entre a biologia e a psicanálise quanto à inscrição da morte na substância viva] logo desaparece [...]"37. Ainda mais porque Freud continua retomando as considerações biológicas sobre esse problema, recorrendo ainda a outros cientistas, mesmo após dizer o que delas quer extrair: "O que nos cativa aqui é a inesperada analogia [Analogie] com nossa própria concepção, desenvolvida por caminhos tão diferentes" ${ }^{38}$. Noutros termos, o recurso à biologia não visa a busca de uma legitimação, e sim de uma inspiração, que é revelada logo que Freud invoca Weismann: a diferenciação da substância viva em uma metade mortal e outra imortal - para o biólogo alemão, o soma e o plasma germinal respectivamente. O que impede a "convergência significativa” entre as concepções dos dois autores é o fato de que essa diferenciação não é válida para organismos pluricelulares, de modo a não poder sustentar morfologicamente a distinção entre pulsões de vida e de morte em animais superiores como o ser humano. Assim, a função da biologia nas especulações filogenéticas é analógica.

Essa constatação pode impressionar, mas, com efeito, temos aí uma indicação epistemológica precisa. Aparentemente, parece escandaloso que a área que gestou e pariu o enfoque evolutivo - isto é, a própria ideia da filogênese e suas formas de investigação - tenha uma utilidade tão secundária. Essa impressão se agrava com a constatação de que Freud vai ancorar sua incursão filogenética em Schopenhauer e Platão, este secundado ainda pelas escrituras hindus. Contudo, Freud indica claramente a independência entre seu campo de investigação e o da biologia:

Nossa expectativa de que a biologia eliminaria o reconhecimento das pulsões de morte [Todestrieb] não foi cumprida. Podemos continuar nos ocupando de sua possibilidade se tivermos outros motivos para fazê-lo. A notável semelhança da distinção de Weismann, entre soma e plasma

\footnotetext{
${ }^{36}$ MAY, The third step in drive theory: on the genesis of Beyond the pleasure principle, 215, 261-267.

${ }^{37}$ FREUD, Jenseits des Lustprinzips, 255.

${ }^{38}$ FREUD, Jenseits des Lustprinzips, 255, grifos meus.
} 
germinal, com nossa divisão entre pulsões de morte e pulsões de vida [Lebenstriebe] permanece, contudo, e mantém seu valor ${ }^{39}$.

Ora, nunca custa lembrar, a preocupação de Freud é de natureza diversa da verificada na biologia. Recordemos: toda essa especulação foi motivada por uma série de fenômenos clínicos. Mais precisamente, trata-se de elucidar o obscuro fenômeno da compulsão à repetição, como se frisou acima. Desse modo, trata-se de buscar na biologia algo que possa esclarecer a natureza dessa repetição. Como David-Ménard indica, o recurso freudiano a essa área no texto em questão "serve para formular um conceito original da repetição que dá conta de casos nos quais a repetição chega a não produzir o idêntico, isto é, a destruição" ${ }^{40}$. Noutros termos, tal recurso se presta a captar um fenômeno que não é a morte propriamente, mas uma mortificação; não a destruição, mas uma destrutividade; enfim, não o inorgânico, mas uma tendência a ele.

Desse modo, em chave negativa, podemos derivar dessas indicações de Freud a independência do campo psicanalítico em relação à biologia evolucionária, mas em chave positiva devemos reconhecer o quanto ele deve a ela, sobretudo no que diz respeito à metapsicologia. Forjar um "conceito original de repetição" suscitou o recurso a uma diretriz metodológica de natureza genética - ou, para usarmos os termos que Freud emprega no texto em questão, "mecânica" e "histórica". Ora, como se viu, esse recurso é feito na linguagem da biologia e, ademais, em diálogo com elementos desta. Afinal, ela se afigurava "um campo de possibilidades ilimitadas" ${ }_{41}$ para o autor. As últimas palavras para designar sua relação com ela, empregadas ao final daquele sexto capítulo, são precisas: "não posso negar que certas analogias, conexões, relações com ela [a biologia] me pareceram dignas de atenção" ${ }^{42}$. Pois nesse deslizamento de caracterizações fica clara tanto a independência quanto a dívida da especulação ou da metapsicologia de Freud em relação à biologia.

Portanto, assim como em Projeto de uma psicologia, a explicação filogenética ganha peso em Além do princípio do prazer apenas após serem exauridas as possibilidades explicativas da compulsão à repetição ao nível ontogenético. Essa constatação não apenas confere robustez à refutação da redução da especulação freudiana nesse texto centenário a um mero exercício metafísico. Nesse sentido, talvez fosse mais preciso chamá-la, como Ferenczi o fazia, de "metabiologia" ${ }^{43}$. Acima de tudo, nossa constatação indica que temos diante de nós um velho um modelo explicativo, que veio à tona progressivamente nos

\footnotetext{
${ }^{39}$ FREUD, Jenseits des Lustprinzips, 258.

40 DAVID-MÉNARD, Como ler Além do princípio do prazer?, 108, grifos meus.

${ }^{41}$ FREUD, Jenseits des Lustprinzips, 268.

${ }^{42}$ FREUD, Jenseits des Lustprinzips, 269, grifos meus.

${ }^{43}$ GRUBRICH-SIMITIS, Metapsychology and Metabiology, 92.
} 
escritos de Freud ${ }^{44}$, o que denota a incompreensão das atitudes de estranhamento e dos esforços hermenêuticos de exclusão das incursões filogenéticas do autor.

\section{Psicanálise e biologia a partir de Além do princípio do prazer. horizontes}

A análise acima mostrou as particularidades da incursão filogenética freudiana em Além do princípio do prazer quando comparada com a da biologia. De fato, por um lado, mesmo no interior da obra freudiana, tal incursão se revela bastante particular, como indica Laplanche ${ }^{45}$. Muito mais frequentemente, Freud recorre à filogênese em seus escritos a fim de perscrutar a gênese das fantasias originárias (Urphantasien), e não a da própria pulsão. Assim, se quiséssemos seguir a partir dessa distinção sinalizada por Laplanche, teríamos dois caminhos para percorrer o filogenético em Freud: um que derivaria das questões levantadas desde a teoria da sedução e do complexo de Édipo, e outra que partiria em busca da elucidação da origem das pulsões e dos instintos ${ }^{46}$. Por outro lado, contudo, o que procuramos mostrar foi que, independentemente de tais caminhos e da natureza da incursão, um mesmo modus operandi se repete para buscar o filogenético.

Ao passo que, durante boa parte do século XX, essas particularidades, conquanto quase completamente relegadas pela literatura de comentário, serviram de motor para um distanciamento ainda maior entre psicanálise e biologia - e mesmo entre boa parte dos pós-freudianos e a própria noção de pulsão de morte ${ }^{47}$-, os últimos trinta anos abrigaram aproximações. David-Ménard ${ }^{48}$ nota que a linguagem empregada por Freud em Além do princípio do prazer, assinalada acima, é a do que hoje se chama de "Evo-Devo", isto é, da biologia evolucionária do desenvolvimento. E realmente, como mostrou Hofer, o entendimento que se tem hoje, organizado por essa nova área, a respeito da ação dos genes e de seus processos de regulação durante o desenvolvimento, bem como dos fenômenos epigenéticos, "reconduziu a compreensão da biologia a uma posição muito mais favorável à formulação psicanalítica de Freud do que em qualquer outro momento desde o final do século XIX”49. Ainda, conforme salienta Green, podemos dizer hoje, a partir dos estudos sobre a apoptose, que "a morte está no cerne do vivo" 50 , como queria Freud.

\footnotetext{
${ }^{44}$ Em FERRETTI, Ontogênese e filogênese em Freud: uma visão de conjunto, busco demonstrar como isso advém na obra freudiana a partir de Totem e tabu, obra a qual analiso sob essa perspectiva.

${ }^{45}$ LAPLANCHE, Introduzione al tema della filogenesi, 908.

${ }^{46}$ LAPLANCHE, Introduzione al tema della filogenesi, 902-903.

${ }^{47}$ GREEN, Négatif et négation em psychanalyse, 145.

48 DAVID-MÉNARD, Como ler Além do princípio do prazer?, 105.

${ }^{49}$ HOFER, The emerging synthesis of development and evolution: a new biology for psychoanalysis, 15.

${ }^{50}$ GREEN, Négatif et négation em psychanalyse, 146.
} 
Não se trata de concluir, de modo algum, deixando-nos guiar pelo ingênuo exercício da ilusão retrospectiva, que haveria um caráter visionário nas especulações freudianas daquele ensaio publicado há cem anos, e sim de ressaltar que as tentativas de aproximação entre psicanálise e biologia as quais vêm sendo feitas nos últimos anos o tornaram ainda mais atual. Muito já disse sobre sua atualidade clínica, mas é preciso também recordar essa outra espécie de atualidade. Assim, ao lado da ênfase na importância de Além do princípio do prazer para a compreensão de quadros que hoje nos desafiam, como os de autismo, borderline, transtornos alimentares e certas psicoses, deve-se ressaltar também que o texto é construído a partir de uma relação com a ciência biológica que hoje gera uma profusão de investigações.

\section{Referências}

CAROPRESO, F.; SIMANKE, R. T. Compulsão à repetição: um retorno às origens da metapsicologia freudiana. Agora, Rio de Janeiro, v. IX, n. 2, p. 207-224, jul./dez. 2006. Disponível em: <https://www.scielo.br/pdf/agora/v9n2/a04v9n2.pdf>. Acesso em: 09 jun. 2020.

DAVID-MÉNARD, M. Como ler Além do princípio do prazer? Reverso, Belo Horizonte, v. 37, n. 69, p. 99-112, jun. 2015. Disponível em: <http://pepsic.bvsalud.org/pdf/reverso/v37n69/v37n69a11.pdf>. Acesso em: 09 jun. 2020.

FERRETTI, M. G. Ontogênese e filogênese em Freud: uma visão de conjunto. Tese (Doutorado) - Instituto de Filosofia e Ciências Humanas, Universidade Estadual de Campinas, Campinas, 2014.

FREUD, S. (1920). Jenseits des Lustprinzips. Frankfurt: Fischer Taschenbuch Verlag, 2000. (Studienausgabe, v. 3).

FREUD, S. (1950). Entwurf einer Psychologie. Frankfurt: S. Fischer Verlag, 1987. (Gesammelte Werke, Nachtragsband).

GABBI JR., O. F. Notas a Projeto de uma psicologia: as origens utilitaristas da psicanálise. Rio de Janeiro: Imago, 2003.

GIACOIA JUNIOR, O. Além do princípio do prazer: um dualismo incontornável. Rio de Janeiro: Civilização Brasileira, 2008.

GREEN, A. Négatif et négation en psychanalyse. In: Heritier et al. Le corps, le sens. Paris: Seuil, 2002.

GRUBRICH-SIMITIS, I. Metapsychology and Metabiology. In: Grubrich-Simitis, I. (Ed.) $A$ Phylogenetic Fantasy: Overview of the Transference Neuroses. Trad. Axel Hoffer e Peter 
T. Hoffer. Cambridge, MA, e Londres: The Belknap Press of Harvard University Press, 1987.

HOFER, M. A. The emerging synthesis of development and evolution: a new biology for psychoanalysis. Neuropsychoanalysis, Londres, v. 16, n. 1, p. 3-22, 2014. Disponível em: $<$ https://www.tandfonline.com/doi/abs/10.1080/15294145.2014.901022>. Acesso em: 09 jun. 2020.

LAPLANCHE, J. Introduzione al tema della filogenesi. Rivista di Psicoanalisi, Milão, v. 55, n. 4, p. 901-912, 2009. Disponível em: < $\underline{\text { https://www.pep- }}$ web.org/document.php?id=rpsa.055.0901a >. Acesso em: 09 jun. 2020.

MAY, U. The third step in drive theory: on the genesis of Beyond the pleasure principle. Psychoanalysis and History, Edimburgo, v. 17, n. 2, p. 205-280, 2015. Disponível em: <https:/www.euppublishing.com/doi/abs/10.3366/pah.2015.0170>. Acesso em: 09 jun. 2020.

MONZANI, L. R. Freud, o movimento de um pensamento. Campinas: Unicamp, 1989.

SIMANKE, R. T. Mente, cérebro e consciência nos primórdios da metapsicologia freudiana: uma análise do Projeto de uma psicologia). São Carlos: EDUFSCar, 2007.

STRACHEY, J. Editor's introduction. In: Freud, S. Pre-psycho-analytic publications and unplubished drafts. Londres: The Hogarth Press, 1966. (The Standard Edition of the Complete Psychological Works of Sigmund Freud, v.1)

SUlloWAY, F. J. Freud, Biologist of the Mind - beyond the psychoanalytic legend. Massachusetts: Harvard University Press, 1992.

YOUNG, R. M. Mind, brain, and adaptation in the nineteenth century: cerebral localization and its biological context from Gall to Ferrier. Nova York: Oxford University Press, 1990. 